\title{
Studi Evaluasi Sistem Saluran Sekunder Drainase Tambaksari kota Surabaya
}

\author{
Edy Sumirman, Ismail Sa'ud, Akhmad Yusuf Zuhdi \\ Program Studi Diploma Teknik Sipil FTSP ITS \\ Email :edysumirman@gmail.com
}

\begin{abstract}
During rainy season, run off inundation happened on parts of Surabaya City, especially on Tambaksari district. In heavy rain, floods happened along road and built area. The problem is caused by inappropriate secondary drainage, so reevaluation of this area needed. Scope of the evaluation is just Tambaksari secondary drainage by dimensions, land use and drainage capacity. Step of calculation consists of rain intencity, discharge debit, and then compared to existing drainage capacity. Calculation of ditch dimensions is based on discharge debit using 5 year return period and existing land use on Tambaksari district.

Using result of the calculation between discharge and existing ditch capacity, there are 11 ditch are inundation by recalculation secondary ditch dimensions, flood on the road and on the area can be managed.
\end{abstract}

Keywords : flood, ditch capacity, dimension

\begin{abstract}
Abstrak
Pada musim hujan genangan terjadi disebagian Kota Surabaya khususnya di kawasan Tambaksari. Pada saat curah hujan yang tinggi sering terjadi genangan pada badan jalan dan bangunan disekitarnya. Permasalahan banjir yang terjadi berasal dari permasalahan saluran sekunder drainase sehingga perlu dilakukkan studi untuk mengevaluasi kembali sistem drainase yang ada. Sistem drainase yang dievaluasi hanya pada saluran sekunder Tambaksari. Dimana yang dievaluasi meliputi dimensi saluran, tata guna lahan dan kapasitas saluran sekunder.

Tahapan perhitungan meliputi perhitungan intensitas hujan, perhitungan debit banjir rencana kemudian dibandingkan dengan kapasitas saluran yang ada. Perhitungan dimensi saluran rencana berdasarkan debit hujan rencana pada periode ulang 5 tahun dan tata guna lahan pada kawasan Tambaksari. Berdasarkan hasil perhitungan antara debit rencana dengan debit saluran sekarang ada 11 saluran yang terjadi genangan. Solusi untuk mengatasi masalah tersebut adalah dengan merencanakan kembali dimensi saluran sekunder sehingga tidak terjadi genangan baik di jalan raya maupun di pemukiman sekitar.
\end{abstract}

Kata Kunci: Genangan, Curah hujan, Kapasitas saluran, Dimensi, Bamjir Tambaksari 


\section{PENDAHULUAN}

\subsection{Latar Belakang}

Seiring dengan perkembangan kota yang sangat pesat di Indonesia, permasalahan mengenai air semakin meningkat pula. Pada umumnya permasalahan mengenai air yang tidak bisa dikendalikan akan menyebabkan bencana, contoh yang sering muncul adalah permasalahan tentang banjir dan genangan.

Permasalahan banjir seharusnya bisa diatasi jika sistem drainase diwilayah tersebut bisa direncanakan dengan baik dan benar. Terutama dikota-kota besar seperti Kota Surabaya. Maka dari itulah yang mendasarkan dilaksanakan studi evaluasi tentang sistem drainase dikota Surabaya khususnya diwilayah Tambaksari.

\subsection{Rumusan Masalah}

Pada musim hujan kondisi saluran sekunder di daerah Tambaksari Surabaya tidak mampu menampung debit banjir sehingga sering terjadi banjir.

\subsection{Batasan Masalah}

Studi evaluasi sistem drainase saluran sekunder di Daerah Tambaksari dan kapasitas Saluran Sekunder Tambaksari yang direncanakan untuk menampung limpasan air hujan dan air buangan.

\subsection{Tujuan}

Adapun tujuan dari penelitian ini untuk mencari penyebab terjadinya banjir di Daerah Tambaksari dan mencari solusi untuk mengatasi banjir tersebut.

\subsection{Manfaat}

Dari hasil Studi Evalusi Sistem Saluran Sekunder Drainase Tambaksari Kota Surabaya ini bisa mengetahui daya tampung saluran dan solusi apa yang dibutuhkan untuk mengatasi banjir di daerah Tambaksari.

\section{METODOLOGI}

\subsection{Persiapan}

Kegiatan mula-mula dalam melakukan studi adalah melakukan persiapan hal ini sangat penting dilakukan yang meliputi persiapan perijinan dan pihak mana yang dapat dihubungi terkait dengan keperluan studi

\section{Gambar 1 Peta Study}

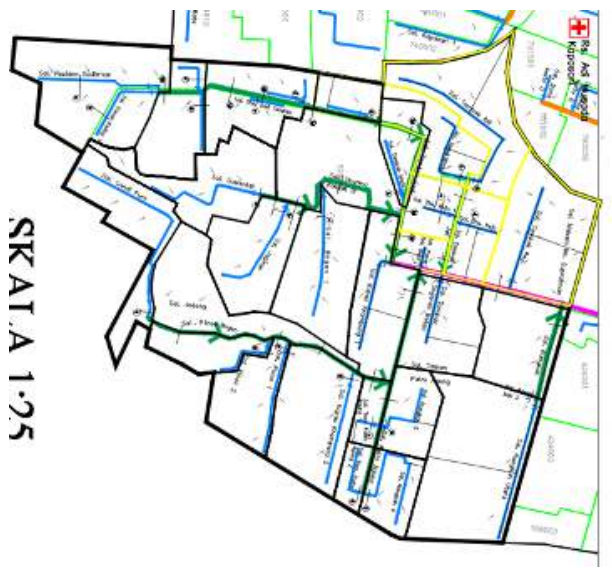

\subsection{Survey Lapangan}

Melakukan peninjauan ke lokasi studi yaitu untuk mengetahui keadaan eksisting dari saluran drainase yang nantinya datanya digunakan untuk menentukan keputusan yang akan diambil sehubungan dengan studi evaluasi yang dilakukan. 
ISSN.1907-753X

\subsection{Studi Literatur}

Mempelajari teori-teori yang bersangkutan dengan tugas akhir berjudul "Perencanaan Sistem Saluran Drainase Sekunder di Daerah Tambaksari".

\subsection{Pengumpulan Data}

Data-data yang menunjang dan digunakan dalam pengamatan sebagai berikut:

1. Peta kontur

2. Curah hujan

3. Peta catchment area

4. Peta lokasi

5. Data eksisting saluran

6. Data hidrologi

7. Data genangan

8. Dll.

\subsection{Analisis Data}

\subsubsection{Analisa Debit Rencana Banjir}

Debit banjir rencana pada umumnya direncanakan untuk mengalirkan air banjir secepatnya, agar tidak terjadi genangan air yang mengganggu aktifitas masyarakat. Oleh karena itu saluran-saluran drainase sebaiknya direncanakan sesuai dengan debit banjir rencana.

Perhitungan curah hujan rencana dapat dihitung dengan menggunakan beberapa metode antara lain adalah Distribusi Gumbel, dan Distribusi Log Person Type III. Adapun sifat-sifat khas parameter statistik dari masing-masing distribusi teoritis dapat dilihat pada tabel 1

\subsubsection{Analisis Intensitas Hujan}

Besar intensitas hujan berbeda-beda. Waktu curah hujan sangat mempengaruhi besar kecilnya intensitas hujan. Karena data yang tersedia hanya data curah hujan harian saja, maka perhitungan intensitas hujan menggunakan rumus Mononobe, yaitu:

$I_{t}=\frac{F_{24}}{24} \times\left[\frac{24}{T_{e}}\right]^{2 / 3}$

Dengan:

$\mathrm{I}_{\mathrm{t}}=$ Intensitas hujan dalam 1 jam (mm/jam)

$\mathrm{R}_{24}=$ Curah hujan efektif dalam $1 \mathrm{jam}$

$\mathrm{T}_{\mathrm{c}}=$ Waktu konsentasi

\subsubsection{Intensitas Hujan Eksisting}

Intensitas hujan eksisting dihitung menggunakan rumus Mononobe dengan menggunakan curah hujan harian maksimum selama 15 tahun terakhir.

Tabel 1. Parameter statistik yang menentukan distribusi

\begin{tabular}{|c|c|c|c|}
\hline \multicolumn{2}{|c|}{ Distribusi } & \multicolumn{2}{|c|}{ Syarat Nilai } \\
\hline \multicolumn{2}{|c|}{ Gumbel } & & $\begin{array}{c}\mathrm{Cs}=1.14 \\
\mathrm{Ck}=5.4\end{array}$ \\
\hline \multicolumn{2}{|c|}{$\begin{array}{c}\text { Log Pearson } \\
\text { III }\end{array}$} & & $\begin{array}{l}\text { bebas } \\
\text { bebas }\end{array}$ \\
\hline \multicolumn{4}{|c|}{ (Sumber: Triatmodjo, 2008: 250) } \\
\hline \multicolumn{4}{|c|}{ Tabel 2. Data Hujan Kawasan Tambaksari } \\
\hline Tahun & Tanggal & $\begin{array}{c}\text { Stasiun } \\
\text { Hujan (mm) } \\
\text { Gubeng }\end{array}$ & $\begin{array}{c}\text { Hujan } \\
\text { Harian (X) } \\
\text { mm }\end{array}$ \\
\hline 2000 & 25 maret & 93 & 93 \\
\hline 2001 & 21 desember & 120 & 120 \\
\hline 2002 & 30 januari & 70 & 70 \\
\hline 2003 & 27 nopember & 68 & 68 \\
\hline 2004 & 7 januari & 58 & 58 \\
\hline 2005 & 8 maret & 89 & 89 \\
\hline 2006 & 14 januari & 106 & 106 \\
\hline 2007 & 18 desember & 104 & 104 \\
\hline 2008 & 14 desember & 98 & 98 \\
\hline 2009 & 28 nopember & 86 & 86 \\
\hline 2010 & 3 desember & 106 & 106 \\
\hline 2011 & 9 nopember & 81 & 81 \\
\hline 2012 & 27 desember & 68 & 68 \\
\hline 2013 & 2 januari & 99 & 99 \\
\hline 2014 & 19 desember & 109 & 109 \\
\hline
\end{tabular}




\subsubsection{Intensitas Hujan Eksisting} Intensitas hujan periode ulang 5 tahun ini dihitung menggunakan rumus Mononobe dengan menggunakan curah hujan harian maksimum periode ulang 5 tahun metode Log Pearson Type III. Intensitas hujan 5 tahun digunakan untuk mengetahui debit rencana 5 tahun yang digunakan untuk mendesain saluran sekunder drainase perkotaan di daerah Tambaksari. Perhitungannya dapat dilihat pada tabel 4.21.

Contoh perhitungan intensitas hujan periode 5 tahun di saluran sekunder Tambaksari adalah sebagai berikut:

$$
\begin{aligned}
& \mathrm{I}_{\mathrm{t}}=\frac{\mathrm{F}_{24}}{24} \times\left[\frac{24}{\mathrm{~T}_{\mathrm{c}}}\right]^{2 / 3} \\
& \mathrm{I}_{\mathrm{t}}=\frac{104, \pi 2}{24} \times\left[\frac{24}{0,25 \mathrm{~s}}\right]^{2 / 3} \\
& \mathrm{I}_{t}=90,856 \mathrm{~mm} / \mathrm{jam}
\end{aligned}
$$

\begin{tabular}{|c|c|c|c|c|c|}
\hline No & Nama Saluran & $\begin{array}{l}\text { Tc } \\
\text { jam }\end{array}$ & & $\begin{array}{l}\mathrm{R} 24 \\
\mathrm{~mm}\end{array}$ & $\begin{array}{c}\mathrm{I} \\
\mathrm{mm} / \mathrm{jam}\end{array}$ \\
\hline 1 & Saluran sekunder 1.1 & 0.253 & & 101.72 & 90.856 \\
\hline 2 & Saluran sekunder 1.2 & 0.660 & & 104.72 & 47.875 \\
\hline 3 & Saluran sekunder 1.3 & 1.048 & & 104.72 & 35.190 \\
\hline 4 & Saluran sekunder 1.4 & 1.368 & & 104.72 & 29.462 \\
\hline 5 & Saluran sekunder 1.5 & 1.566 & & 104.72 & 26.925 \\
\hline 6 & Saluran sekunder 1.6 & 1.832 & & 104.72 & 24.249 \\
\hline 7 & Saluran sekunder 1.7 & 2.081 & & 104.72 & 22.270 \\
\hline 1 & Saluran sekunder 2.1 & 0.293 & & 104.72 & 82.217 \\
\hline 2 & Saluran sekunder 2.2 & 0.880 & & 104.72 & 39.529 \\
\hline 3 & Saluran sekunder 2.3 & 1.463 & & 104.72 & 28.177 \\
\hline 4 & Saluran sekunder 2.4 & 1.922 & & 104.72 & 23.486 \\
\hline 1 & Saluran sekunder 3.1 & 0.668 & & 104.72 & 47.490 \\
\hline 2 & Saluran sekunder 3.2 & 0.978 & & 104.72 & 36.850 \\
\hline 3 & Saluran sekunder 3.3 & 1.458 & & 104.72 & 28.239 \\
\hline 4 & Saluran sekunder 3.4 & 1.905 & & 104.72 & 23.627 \\
\hline 5 & Saluran sekunder 3.5 & 2.304 & & 104.72 & 20.809 \\
\hline No & Nama Saluran & $\mathrm{C}$ & $\begin{array}{c}\mathrm{I} \\
\mathrm{mm} / \mathrm{jam}\end{array}$ & $\begin{array}{c}\mathrm{A} \\
\mathrm{Km}^{2}\end{array}$ & $\begin{array}{c}\text { Q rencana } \\
\mathrm{m}^{3} / \text { det }\end{array}$ \\
\hline 1 & Saluran teriser $4 \mathrm{a}$ & 0.498 & 18.263 & 0.024 & 0.061 \\
\hline 2 & Saluran teriser $4 \mathrm{~b}$ & 0.498 & 8.146 & 0.052 & 0.059 \\
\hline 3 & Saluran tersier $4 \mathrm{c}$ & 0.498 & 37.403 & 0.025 & 0.129 \\
\hline 4 & Saluran tersier $4 \mathrm{~d}$ & 0.498 & 16.408 & 0.058 & 0.132 \\
\hline 1 & Saluran tersier $5 \mathrm{a}$ & 0.498 & 6.351 & 0.076 & 0.067 \\
\hline 2 & Saluran teriser $5 \mathrm{~b}$ & 0.498 & 10.019 & 0.126 & 0.175 \\
\hline 3 & Saluran tersier $5 \mathrm{c}$ & 0.498 & 20.105 & 0.165 & 0.459 \\
\hline 4 & Saluran tersier $5 \mathrm{~d}$ & 0.498 & 9.135 & 0.051 & 0.064 \\
\hline
\end{tabular}

Tabel 3 Perhitungan Intensitas Hujan Periode Ulang 5 Tahun 


\section{ISSN.1907-753X}

Berikut ini adalah adalah contoh perhitungan debit rencana pada saluran tersier Tambaksari menggunakan metode rasional.

Diketahui:

$\mathrm{Q}=\frac{1}{3,6} \times \mathrm{C} \times:_{\mathrm{t}} \times \mathrm{A}$

$\mathrm{Q}=\frac{1}{3,6} \times \mathrm{C} \times:_{\mathrm{t}} \times \mathrm{A}$

$\mathrm{Q}=\frac{1}{3,6} \times 0,477 \times 44,247 \mathrm{mr} / \mathrm{am} \times \mathrm{C}, 136 \mathrm{~km}^{2}$

$\mathrm{Q}=0,832 \mathrm{~m}^{3} / \mathrm{det}$

Dengan:

$\mathrm{Q}=$ Debit puncak $\left(\mathrm{m}^{3} / \mathrm{det}\right)$

$\mathrm{C}=$ Koefisien pengaliran

I = Intensitas curah hujan $(\mathrm{mm} / \mathrm{jam})$

A $=$ Luas daerah pengaliran $\left(\mathrm{km}^{2}\right)$

\subsubsection{Perbandingan Data}

Perbandingan kapasitas saluran eksisting dengan debit rencana adalah cara membandingkan kapasitas saluran dengan debit rencana. Apabila kapasitas saluran eksisting lebih besar daripada debit rencana, maka saluran tersebut dikatakan aman. Tetapi apabila kapasitas saluran eksisting lebih kecil tersebut banjir.

\section{HASIL EVALUASI}

Dari Hasil Studi Evaluasi Sitem Sekunder Drainase Tambaksari Kota Surabaya. Diperlukan penanganan genangan di kawasan Tambaksari dengan cara revitalisasi sistem, yang harus mengacu secara menyeluruh terhadap kondisi la pangan yang ada. Kegiatan-kegiatan yang termasuk adalah sebagai berikut:

1. Mengoptimalkan kapasitas yang ada.
Kegiatan ini mencakup perbaikan dan peningkatan kapasitas saluran dan bangunan pelengkap yang telah ada.

2. Pembangunan saluran baru.

Yaitu dengan memperbesar dimensi saluran dengan rumus manning yang seharusnya rumus ini digunakan untuk saluran seragam bukan untuk saluran tidak seragam agar memenuhi kebutuhan dan pembangunan saluran-saluran baru.

3. Pembangunan pintu air dan pompa.

Merupakan bangunan tambahan untuk menutup debit yang masuk dari saluran sekunder ke outlet pada saat terjadi hujan maksimum. Pompa untuk melimpaskan debit yang telah ditutup oleh pintu air pada saat terjadi hujan maksimum. Pompa dan pintu air direncanakan dibangun pada hilir dari saluran sekunder yang masuk ke saluran primer. Dimensi pintu air disesuaikan dengan dimensi hilir saluran sekunder.

\section{KESIMPULAN}

- Penyebab terjadinya genangan/banjir di daerah Tambaksari akibat dari dimensi saluran sekunder yang tidak mampu menampung debit banjir dan terjadi endapan pada saluran.

- Saluran di Tambaksari sebagian tidak bisa menampung air pada waktu intensitas hujan maksimum dikarenakan $\mathrm{Q}$ eksisting $<$ Q rencana. Saluran yang meluber adalah saluran 
Tabel 4 Debit Rencana Saluran Sekunder 5 Tahun

\begin{tabular}{|c|c|c|c|c|c|}
\hline No & Nama Saluran & $\mathrm{C}$ & $\begin{array}{c}\mathrm{I} \\
\mathrm{mm} / \mathrm{jam} \\
\end{array}$ & $\begin{array}{c}\mathrm{A} \\
\mathrm{km} 2 \\
\end{array}$ & $\begin{array}{c}\text { Q rencana } \\
\mathrm{m}^{3} / \text { det }\end{array}$ \\
\hline 1 & Saluran sekunder 1.1 & 0.498 & 90.856 & 0.171 & 2.149 \\
\hline 2 & Saluran sekunder 1.2 & 0.498 & 47.875 & 0.251 & 1.662 \\
\hline 3 & Saluran sekunder 1.3 & 0.498 & 35.190 & 0.349 & 1.699 \\
\hline 4 & Saluran sekunder 1.4 & 0.498 & 29.462 & 0.382 & 1.557 \\
\hline 5 & Saluran sekunder 1.5 & 0.498 & 26.925 & 0.429 & 1.598 \\
\hline 6 & Saluran sekunder 1.6 & 0.498 & 24.249 & 0.658 & 2.207 \\
\hline 7 & Saluran sekunder 1.7 & 0.498 & 22.270 & 0.658 & 2.207 \\
\hline 1 & Saluran sekunder 2.1 & 0.498 & 82.217 & 0.109 & 1.240 \\
\hline 2 & Saluran sekunder 2.2 & 0.498 & 39.529 & 0.209 & 1.143 \\
\hline 3 & Saluran sekunder 2.3 & 0.498 & 28.177 & 0.335 & 1.306 \\
\hline 4 & Saluran sekunder 2.4 & 0.498 & 23.486 & 0.380 & 1.235 \\
\hline 1 & Saluran sekunder 3.1 & 0.498 & 47.490 & 0.103 & 0.677 \\
\hline 2 & Saluran sekunder 3.2 & 0.498 & 36.850 & 0.152 & 0.775 \\
\hline 3 & Saluran sekunder 3.3 & 0.498 & 28.239 & 0.226 & 0.883 \\
\hline 4 & Saluran sekunder 3.4 & 0.498 & 23.627 & 0.355 & 1.160 \\
\hline 5 & Saluran sekunder 3.5 & 0.498 & 20.809 & 0.355 & 1.022 \\
\hline 1 & Saluran sekunder 4.1 & 0.498 & 95.973 & 0.076 & 1.009 \\
\hline 2 & Saluran sekunder 4.2 & 0.498 & 57.707 & 0.159 & 1.269 \\
\hline 3 & Saluran sekunder 4.3 & 0.498 & 36.723 & 0.199 & 1.011 \\
\hline 4 & Saluran sekunder 4.4 & 0.498 & 28.610 & 0.215 & 0.851 \\
\hline 1 & Saluran sekunder 5.1 & 0.498 & 45.859 & 0.201 & 1.275 \\
\hline 2 & Saluran sekunder 5.2 & 0.498 & 28.541 & 0.293 & 1.157 \\
\hline 3 & Saluran sekunder 5.3 & 0.498 & 21.900 & 0.418 & 1.266 \\
\hline
\end{tabular}

sekunder 1.1 sampai saluran sekunder 1.7, saluran sekunder 2.2, saluran sekunder 2.3, saluran sekunder 3.4, saluran sekunder 3.5, saluran sekunder 5.1, saluran sekunder 5.2, saluran sekunder 5.3.
- Dilakukan redesain pada saluran yang meluber dengan dimensi lebar saluran $4 \mathrm{~m}$ dan tinggi saluran antara $1,4 \mathrm{~m}-2,5 \mathrm{~m}$. 
Jurnal Aplikasi Teknik Sipil

\section{ISSN.1907-753X}

Tabel 5 Perbandingan Debit Rencana Periode 5 Tahun Saluran Sekunder

\begin{tabular}{llccc}
\hline No & Nama saluran & $\begin{array}{c}\text { Q eksisting } \\
\left(\mathrm{m}^{3} / \mathrm{det}\right)\end{array}$ & $\begin{array}{c}\text { Q rencana } \\
\left(\mathrm{m}^{3} / \mathrm{det}\right)\end{array}$ & Keterangan \\
\hline 1 & Saluran sekunder 1.1 & 2.895 & 3.207 & meluber \\
2 & Saluran sekunder 1.2 & 2.895 & 5.667 & meluber \\
3 & Saluran sekunder 1.3 & 3.155 & 7.726 & meluber \\
4 & Saluran sekunder 1.4 & 3.417 & 9.663 & meluber \\
5 & Saluran sekunder 1.5 & 3.417 & 11.832 & meluber \\
6 & Saluran sekunder 1.6 & 12.437 & 14.247 & meluber \\
7 & Saluran sekunder 1.7 & 12.437 & 21.664 & meluber \\
& & & & \\
1 & Saluran sekunder 2.1 & 2.010 & 1.441 & aman \\
2 & Saluran sekunder 2.2 & 2.010 & 2.707 & meluber \\
3 & Saluran sekunder 2.3 & 2.010 & 4.155 & meluber \\
4 & Saluran sekunder 2.4 & 7.182 & 5.390 & aman \\
& & & & aman \\
1 & Saluran sekunder 3.1 & 2.868 & 0.771 & aman \\
2 & Saluran sekunder 3.2 & 2.868 & 1.638 & aman \\
3 & Saluran sekunder 3.3 & 2.868 & 2.622 & meluber \\
4 & Saluran sekunder 3.4 & 2.868 & 3.977 & meluber \\
5 & Saluran sekunder 3.5 & 2.868 & 4.999 & aman \\
& & & & aman \\
1 & Saluran sekunder 4.1 & 4.164 & 1.128 & aman \\
2 & Saluran sekunder 4.2 & 4.164 & 2.658 & aman \\
3 & Saluran sekunder 4.3 & 4.164 & 3.669 & meluber \\
4 & Saluran sekunder 4.4 & 7.127 & 4.520 & meluber \\
& & & 1.517 & meluber \\
\hline 1 & Saluran sekunder 5.1 & 1.473 & 4.197 & \\
2 & Saluran sekunder 5.2 & 1.473 & & \\
3 & Saluran sekunder 5.3 & 2.057 & & \\
\hline
\end{tabular}

\section{DAFTAR PUSTAKA}

Anggrahini. (1996). Hidrolika Saluran

Terbuka. Surabaya: CV. Citra Media.

BAPPEKO. (2018). SDMP (Surabaya Drainage Master Plan). Surabaya.

Citra, M. (2009). Studi Sistem Drainase di Kecamatan Tambaksari. Surabaya.

Harto, S. (1993). Analisis Hidrologi. Yogyakarta: PT. Gramedia Pustaka Utama.

Loebis, J. (1984). Banjir Rencana untuk Bangunan Air. Jakarta: Badan Penerbit.
Soemarto, C. (1987). Hidrologi Teknik. Surabaya: Usaha Nasional.

Soewarno. (1995). Hidrologi Aplikasi Metode Statistik untuk Analisa Data. Bandung: NOVA.

Subarkah, I. (1980). Hidrologi untuk Bangunan Air. Bandung: Idea Dharma.

Suripin. (2003). Sistem Drainase yang Berkelanjutan. Semarang: ANDI.

Triatmodjo, B. (2008). Hidrologi Terapan. Yogyakarta: Beta Offset. 
